\title{
Advances and Controversies in the Application of a Modified Version of Cognitive Behavior Therapy for Social Anxiety Disorder
}

\author{
JENNY ROGOJANSKI ${ }^{\mathrm{a}, \mathrm{c}}$ \& SIMON A. REGO ${ }^{\mathrm{b}}$
}

\footnotetext{
${ }^{\mathrm{a}}$ Frederick W. Thompson Anxiety Disorders Centre, Sunnybrook Health Sciences Centre, Toronto, ON, Canada $\mathrm{b}$

bepartment of Psychiatry, Montefiore Medical Center, Bronx, NY, U.S.A

${ }^{\mathrm{C}}$ Correspondence concerning this article should be addressed to Jenny Rogojanski, Frederick W. Thompson Anxiety Disorders Centre, Sunnybrook Health Sciences Centre, 2075 Bayview Avenue, Toronto, ON, M4N 3M5, Canada

Email: jenny.rogojanski@sunnybrook.ca
}

\begin{abstract}
In their comprehensive case study, Jensen, Hougaard, and Fishman (2013) examined the microlevel mechanisms of change for a socially anxious client who underwent one-week of intensive group-based cognitive behavioral therapy (CBT) and experienced rapid symptom improvement. Our commentary focuses on two key components in the cognitive model of social anxiety, which this study highlights - the role of safety behaviors and interrogating the social environment, as well two topics that are applicable to anxiety treatments in general - integrating acceptance-based strategies into CBT and novel approaches in treatment delivery. We highlight what can be learned from Jensen and colleagues' case study by incorporating both empirical research and our own clinical anecdotes.

Key words: cognitive behavior therapy; social anxiety disorder; mechanisms of change; exposure therapy; anxiety; case studies; clinical case studies; case series

We thoroughly enjoyed reading Jensen, Hougaard, and Fishman's (2013) case study of the mechanisms of change in a social phobia client following intensive group-based cognitive behavioral therapy (CBT). This article described Sara, a woman diagnosed with Social Anxiety Disorder who suffered from a primary fear of blushing, and explored mechanisms of change related to her rapid recovery following a brief, intensive treatment. This treatment was based primarily on the work of David Clark and colleagues and comprised of three individual weekly treatment sessions, followed by one week of 5-hour intensive daily group treatment, and five weekly individual follow-up sessions largely for consolidation of treatment gains. Although we're quite familiar with this treatment model and have utilized it with numerous clients individually in our own clinical practices, the authors of this article provide a novel approach for delivering this treatment - in terms of both format and frequency. Being zealous cognitive behavior therapists, we were intrigued by this approach and will focus this commentary on
\end{abstract}


Advances and Controversies in the Application of a Modified Version

advances in the treatment of social anxiety and other topics closely related to exposure-based treatments for this condition, starting with the role of safety behaviors in treatment.

\section{SAFETY BEHAVIORS-FRIEND OR FOE?}

A safety behavior is typically defined as any act that an individual engages in with the intention of this act reducing or minimizing a threat or catastrophe from occurring in a feared situation (Salkovskis, 1991; Wells et al., 1995). As a result, from a cognitive behavioral perspective, safety behaviors have traditionally been considered to pose a threat to successful treatment outcome and, consequently, important to identify and eliminate during the course treatment. Thus, it is no surprise that in the Jensen and colleagues (2013) article, safety behaviors are conceptualized as playing a major role in the maintenance of social anxiety symptoms by interfering with the development of self-efficacy following exposure practices. Specifically, the authors propose that when individuals engage in a safety behavior and their feared catastrophe fails to occur, they will be more likely to attribute the nonoccurrence of the catastrophe to their use of the safety behavior rather than to the situation being less dangerous than they thought. In addition, they will likely fail to recognize their own ability to manage the situation without engaging in the safety behavior, which results in the individuals continuing to experience anxiety in the situation despite repeated exposures to it. Thus, within this framework, it seems reasonable to make one goal of therapy to work with clients on dropping their use of safety behaviors.

However, more recent research casts some doubt on the assertion that safety behaviors are always bad and need to be targeted in treatment, and considers the use of safety behaviors under certain conditions in a more positive light. Although research shows that safety behaviors do have the potential to be counter-productive if they promote a misattribution of safety, or interfere with the development of self-efficacy or other mechanisms of emotional processing during exposure practices (Parrish, Radomsky, \& Dugas, 2008), there is evidence that these strategies are not always detrimental to treatment outcome. In fact, some researchers (e.g., Deacon, Sy, Lickel, \& Nelson, 2010) have found no reliable benefits or drawbacks associated with the judicious use of safety behaviors in exposure therapy, while others (e.g., Milosevic \& Radomsky, 2008; Rachman, Radomsky, \& Shafran, 2008; Rachman, Shafran, Radomsky, \& Zysk, 2011; Sy, Dixon, Lickel, Nelson, \& Deacon, 2011) have found that the judicious use of safety behaviors during graduated exposure exercises may present advantages over traditional exposure-based treatments by allowing clients to: (a) approach their feared situation more rapidly; and (b) stay in that situation for a longer period of time relative to those individuals who are told to drop their use of safety behaviors - both of which may serve to enhance the exposure practice rather than interfere with it. For example, research suggests that safety behaviors that focus on impression management (e.g., behavioral rehearsal, feigning friendly behavior towards others) rather than avoidance (e.g., avoiding eye contact, not speaking) are not typically associated with negative perceptions by others in a social context (Hirsch, Meynen, \& Clark, 2004). It has also been suggested that if these behaviors do not result in negative outcomes for the client, it may not be necessary for the client to stop engaging in them (Parrish et al., 2008). Other research suggests that cautious use of distraction or humor during exposure may also enhance, rather than interfere with, exposure practices (e.g., Ventis, Higbee, \& Murdock, 2001; Johnstone \& Page, 2004; Oliver \& Page, 2003). 
Advances and Controversies in the Application of a Modified Version

Thus, if the extant literature is taken as a whole, we would suggest that perhaps there shouldn't be an absolute edict that safety behaviors should always be targeted within treatment, but rather that the role and use of safety behaviors should always be functionally analyzed and that the information obtained from the analysis should be used to inform the clinician's case conceptualization and treatment targets. In other words, while we agree that the ultimate goal should be for clients to no longer rely on safety behaviors in order to enter or get through feared situations, we would advocate for allowing the use of safety behaviors at the start of treatment in order to help ease clients into the exposure practices, and then encouraging them to gradually reduce their reliance on the safety behaviors as they move up their fear and/or avoidance hierarchy. It should be noted that for some clients, it may not even be necessary to directly target the safety behaviors, because some research (e.g., Milosevic \& Radomsky, 2008) suggests that as they develop a sense of self-efficacy and mastery in their feared situation, clients reduce their reliance on safety behaviors on their own.

Within the case study, it was reported that Sara made use of various safety behaviors prior to beginning treatment, including wearing high necked blouses and hiding her face in order to conceal her blushing from others, but that she was no longer engaging in many of these behaviors when she began treatment (Jensen et al., 2013). Interestingly, however, the authors report that a potentially key remaining safety behavior (carefully monitoring the warmth in her face to detect signs of blushing) was, “...not recorded in the individualized measure of social phobia... since Sara herself did not consider it a form of safety behavior, and her therapist did not insist on doing so.” It also may be worth considering whether the group format of the treatment could itself be considered a type of safety behavior. For example, some of the interventions utilized within the group treatment in order to provide corrective feedback, such as video recordings of behavioral experiments and eliciting feedback from group members regarding Sara's blushing, could be conceptualized as forms of reassurance, which is commonly sought as a safety behavior by anxious clients. Research suggests that individuals with social anxiety disorder experience intolerance of uncertainty, which has been implicated as a central construct in anxiety pathology and is a predictor of social anxiety symptom severity (Boelen \& Reijntjes, 2009). It has been suggested that these individuals may engage in reassurance seeking in order to reduce this feeling of uncertainty (Cougle et al., 2012), which is hypothesized to play a critical role in the maintenance of anxiety (Lohr, Olatunji, \& Sawchuk, 2007).

In addition, when thinking about the video feedback component of treatment specifically, it has been suggested that this intervention may be less helpful for individuals who are concerned about an aspect of their physical appearance rather than their social skills (Moscovitch, 2009), which appears to fit the case of Sara. Experimental research has shown that individuals with high concern about their physical appearance do not benefit from video feedback above and beyond exposure treatment alone (Orr \& Moscovitch, 2013), affirming the importance of adapting treatment procedures to accommodate for the idiosyncratic concerns of socially anxious clients. Thus, when debating whether safety behaviors are a "friend" or "foe" of treatment, it is important to consider that although video feedback and other methods commonly employed in social anxiety and other anxiety disorder treatments, such as role modeling by the therapist, or in this case, soliciting feedback from group members, conducting surveys, and even the use of a group itself as a proxy for the "real world" are not typically conceptualized as safety behaviors, it is possible that clients may view them as such! Perhaps this would explain why these techniques 
Advances and Controversies in the Application of a Modified Version

are not equally effective for all clients. As such, we believe that the function of these behaviors (and interventions) be considered for each client separately, given the idiosyncratic nature of this disorder.

\section{"INTERROGATING THE SOCIAL ENVIRONMENT": A CRITICAL COMPONENT-BUT BASED ON WHICH THEORY?}

Another notion closely related to the above discussion of safety behaviors is termed by Clark (2005) “interrogating the social environment.” According to Clark (2005), repeated exposure practices without the use of safety behaviors are not necessarily helpful for clients with social anxiety. He emphasizes that habituation should not be the goal of exposure practices per se, but rather exposure exercises should be structured in a way that allows the client to test their feared predictions about the social experience in question, in order to facilitate cognitive change that can subsequently lead to symptom reduction. Given that clients with social anxiety tend to have excessively high standards for themselves in social situations, Clark underscores the importance of encouraging clients to test these standards and assumptions by purposely breaking these rules during exposure practices. For example, when thinking about the case of Sara in Jensen and colleagues' (2013) article, an example of an exposure exercise based on Clark's cognitive theory, would be for Sara to conduct a "behavioral experiment" that involves interrogating the social environment by attending a meeting while wearing excessive makeup to simulate blushing and observing the other group members' reactions to her.

However, given that this "interrogation of the social environment” would serve as both an exposure practice and a cognitive exercise designed to test whether Sara's catastrophic predictions about the social consequences of blushing are in fact true, we agree with the authors' assertion (and empathize with their subsequent struggle in interpreting their findings) that their data could theoretically be consistent with several disparate theories of emotional disorders and thus interpreted differently based on these various theoretical perspectives (Jensen et al., 2013). For example, it is difficult to understand how it could not also be ascribed to the modern learning theories of Craske et al. (2008) (i.e., stressing the role of expectancy violation or disconfirmation) and/or the (2006) reformulation of Foa's emotional processing theory (i.e., targeting disconfirmation of specific propositions in the client's fear network).

Regardless of whether interrogation of the social environment is seen as a component of cognitive theory, modern learning theory, or the reformulation of emotional processing theory, we agree that the creation of exercises that test clients' catastrophic predictions is critical to positive treatment outcome. Perhaps the "take home message" for clinicians working with clients with anxiety disorders is to be certain to make explicit with each client the purpose and function of each exposure exercise, by tying each one to a feared prediction that can be tested (and refuted). Some examples of behavioral experiments that we have used with clients with social anxiety in order to test their predictions include purposely dropping papers in a crowded hallway, walking around with a salsa stain on their face and/or clothes, tripping in the cafeteria with a tray full of items in their hands, and asking seemingly obvious and/or nonsensical questions to people in authority - all while observing other peoples' reactions. These exercises, however, could easily be extended to other anxiety disorders, such as having a client with panic disorder feign passing out to see if people would help or not, or having a client with claustrophobia purposely get stuck 
Advances and Controversies in the Application of a Modified Version

in an elevator by pushing the emergency stop button. What they all have in common, however, and what's clearly important for successful treatment outcome, is that they all seek more than habituation to anxiety symptomatology by encouraging clients to break rules that they rigidly uphold in order to violate expectancies and/or disconfirm fear propositions and, in so doing, help clients to develop a sense of self-efficacy (e.g., Bandura, 1977) and "psychological flexibility" in their social environments.

\section{ACCEPTANCE AS A MECHANISM OF ACTION IN THE COGNITIVE MODEL}

The notion of psychological flexibility leads us to comment on an interesting point highlighted by Jensen and colleagues (2013) on the role of acceptance in exposure-based treatments. It was reported that Sara attributed much of her improvement from treatment to her increased acceptance of her blushing and letting go of the need to control her blushing and negative emotions. In fact, the authors emphasized the fact that Sara's acceptance of her negative emotions and physical sensations strongly contributed to her rapid improvement from treatment, hypothesizing that this was one of the main mechanisms involved in her treatment outcome. Acceptance of negative emotions is not often emphasized in CBT in the same way as it is in other so-called "third wave” behavioral treatments, which involve more explicit mindfulness and acceptance-based training practices (Baer, 2005). Treatments such as Acceptance and Commitment Therapy (ACT) move away from emphasizing cognitive change, as is arguably the case in traditional CBT, and focus on changing clients' relationship with their private experiences (e.g., thoughts, memories, bodily sensations) in order to detach from those experiences and be able to live a more flexible and meaningful lives (Hayes, Strosahl, \& Wilson, 1999). Although some argue that the mechanism of change in acceptance-based approaches such as ACT is quite different from traditional CBT, mindfulness practices are conceptually analogous to interoceptive exposure practices (Carmody et al., 2007), such that they facilitate emotional approach coping and acceptance by encouraging individuals to engage in moment-bymoment awareness of negative affective cues without engaging in maladaptive responding to those cues (Baer, 2002). This in turn is thought to help clients build a tolerance to such cues and create a new, more adaptive conditioned response to negative affective cues (Breslin et al., 2002).

Although some argue that traditional "first-wave” (i.e., behavioral) and "second-wave” (i.e., cognitive-behavioral) therapies differ from third-wave (i.e., acceptance and mindfulnessbased) approaches because of the emphasis on acceptance in these approaches and the emphasis on cognitive change in CBT, findings from the current study beg the question, "Are they really that different?" As mentioned within Jensen and colleagues (2013), researchers postulate that there are more similarities than differences between these two approaches (Arch \& Craske, 2008; Hofmann \& Asmundson, 2008; Hofmann, 2008). Similarly, Marsha Linehan (personal communication, August 28, 2007) does not consider Dialectical Behavior Therapy (DBT) to be part of the third wave but, instead, views DBT as a form of classic CBT that includes acceptance strategies (in David \& Hofmann, 2013). Other researchers (e.g., Roemer \& Orsillo, 2002) have also started to incorporate mindfulness and acceptance-based strategies into existing cognitive behavioral models for the treatment of anxiety disorders. Although Sara was not specifically instructed to use any strategies to help her accept her symptoms, her gradual increase in 
Advances and Controversies in the Application of a Modified Version

acceptance of them appears to have played a significant role in her recovery. Thus, acceptance may be an important mediator in terms of treatment outcome for both second-wave and thirdwave treatments, although arguably they may arrive at acceptance through the use of different strategies.

\section{MODIFICATIONS OF THE “STANDARD” TREATMENT: FORMAT AND SESSION DOSING}

Finally, we were intrigued by Jensen and colleagues’ (2013) choice of session “dosing” and method of delivery of their treatment. In this case, Sara received three individual weekly treatment sessions, followed by one week of group treatment delivered in daily, 5-hour sessions, followed by five, once-weekly individual follow-up sessions - which were used not only for consolidation of the gains she made in treatment but also for the targeting of additional problem areas (i.e., her spider phobia). Research suggests that massed-intensive treatments produce effects that are on par or greater than more traditional, once-weekly treatments (e.g., Foa, Jameson, Turner, \& Payne, 1980; Abramowitz, Foa, \& Franklin, 2003; Storch, Merlo, Lehmkuhl, Geffken, Jacob, Ricketts, Murphy, \& Goodman, 2008) and, perhaps equally importantly, that there appears to be no benefit and a greater risk of premature termination from extending the course of CBT treatment over time (Herbert, Rheingold, Gaudiano, \& Meyers, 2004). In addition, research (e.g., Fals-Stewart, Marks, \& Schafer, 1993; Flannery-Schroeder \& Kendall, 2000; Steketee, Frost, Wincze, Greene, \& Douglass, 2000; Anderson \& Rees, 2007) suggests that group modalities can be as effective as individual treatments, when it comes to CBT approaches for the various anxiety disorders. Finally, Sara's rapid response to CBT after only a few group sessions also highlights an interesting phenomenon that has previously been recognized in the literature whereby CBT treatment responders tend to make most of their therapeutic gains in the early sessions of treatment (e.g., Masheb \& Grilo, 2007; Wilson, 2006).

Taken together these results have significant implications from a public health perspective. Specifically, if treatment responders exhibit the majority of their gains from treatment within the first several sessions, there may be a strong rationale for introducing a stepped care approach whereby clients begin treatment with the least costly, least invasive, and most accessible treatment option, and only progress to more comprehensive or expensive treatment options if the less intrusive treatments do not work (Gilliam, Diefenbach, Whiting, \& Tolin, 2010). In addition, if a group format produces results comparable to individual therapy, it could improve access to care and reduce wait times, all while lowering the cost of care. Similarly, if massed-intensive dosing produces results comparable to more traditional, onceweekly sessions, then it may be of benefit for clients who do not have local access to care, are more incapacitated, or have an opportune break in their schedule (e.g., summer holiday, seasonal holidays).

That clients seem to make the majority of their therapeutic gains early on in treatment, however, reinforces the importance of clinicians focusing on establishing a strong therapeutic alliance and, in so doing, "selling” CBT to their clients from the outset (Muller \& Schultz, 2012). Therapeutic alliance early in treatment has been shown to be associated with outcomes (Krupnick et al., 1996), indicating that this is a critical precursor for clients making therapeutic gains in treatment. In addition, studies show us that clients' pretreatment expectancy for change 
Advances and Controversies in the Application of a Modified Version

and early homework compliance are important mediators of treatment outcome and can serve as motivation for therapeutic involvement and subsequent treatment gains (Westra, Dozois, \& Marcus, 2007). These findings, in combination with those of Jensen and colleagues (2013), indicate that regardless of the format, length, or dosing of the treatment, those first few sessions are precious and can have a significant impact on a client's therapeutic trajectory.

Finally, it should be noted that in Jensen and colleagues' (2013) study, the group treatment was administered by students (i.e., paraprofessionals). This may also have important implications for both stepped-care models and the dissemination of evidence-based treatment. Clearly, transitioning to a stepped-care model of treatment delivery would be more cost-effective than administering full and comprehensive treatment packages to all clients, and may also improve client access to care. Similarly, utilizing students or other paraprofessionals instead of costly professionals (i.e., PhDs and PsyDs) could further enhance cost-effectiveness and access to care, while apparently still maintaining treatment integrity and outcome quality. This would be in line with other research (e.g., Foa, Hembree, Cahill, Rauch, Riggs, Feeny, \& Yadin, 2005) that found that treatment in the hands of counselors with minimal CBT experience was as efficacious as that of CBT experts.

\section{CONCLUDING REMARKS}

Jensen, Hougaard, and Fishman (2013) provide an excellent example of a methodology for identifying the micro-level mechanisms of change based on a comprehensive case study of a socially anxious client who underwent a brief, intensive group-based CBT treatment and experienced rapid symptom improvement. The authors highlight the difficulty inherent in investigating micro-level mechanisms of change through the analysis of case studies. However, much can still be learned from this work. The in-depth analysis of Sara's case allows us to build a connection between theoretical and empirical findings and the clinical aspects of CBT. This case study highlights the role of acceptance of symptoms in cognitive change, as well as the controversial role of safety behaviors in social anxiety treatment. Additionally, the format, length, and dosing of the treatment and Sara's rapid recovery early on in treatment has significant implications from a treatment accessibility and dissemination standpoint.

\section{REFERENCES}

Abramowitz, J. S., Foa, E. B., \& Franklin, M. E. (2003). Exposure and ritual prevention for obsessive-compulsive disorder: Effects of intensive versus twice-weekly sessions. Journal of Consulting and Clinical Psychology, 71(2), 394-398.

Anderson, R. A., \& Rees, C. S. (2007). Group versus individual cognitive-behavioural treatment for obsessive-compulsive disorder: a controlled trial. Behaviour Research and Therapy, 45(1), 123-137.

Arch, J. J., \& Craske, M. G. (2008). Acceptance and commitment therapy and cognitive behavioral therapy for anxiety disorders: Different treatments, similar mechanisms?: Clinical Psychology: Science and Practice, 15, 263-279. doi:10.1111/j.14682850.2008.00137.x

Baer, J. (2002). Student factors: Understanding individual variation in college drinking. Journal of Studies on Alcohol, 14, 40-53. 
Advances and Controversies in the Application of a Modified Version

Baer, R. A. (2005). The third wave: New directions in cognitive-behavioral intervention. PsycCRITIQUES, 50, n.p.

Bandura, A. (1977). Self-efficacy: Towards a unifying theory of behavioral change. Psychological Review, 84, 191-215.

Boelen, P. A., \& Reijntjes, A. (2009). Intolerance of uncertainty and social anxiety. Journal of Anxiety Disorders, 23, 130-135. doi:10.1016/j.janxdis.2008.04.007

Breslin, F., Zack, M., \& McMain, S. (2002). An information-processing analysis of mindfulness: Implications for relapse prevention in the treatment of substance abuse. Clinical Psychology: Science and Practice, 9, 275-299.

Carmody, T. P., Vieten, C., \& Astin, J. A. (2007). Negative affect, emotional acceptance, and smoking cessation. Journal of Psychoactive Drugs, 39, 499-508.

Clark, D. M. (2005). A Cognitive Perspective on Social Phobia. In W. R. Crozier \& L. E. Alden (Eds.), The essential handbook of social anxiety for clinicians (pp. 405-430). West Sussex, England: John Wiley.

Cougle, J. R., Fitch, K. E., Fincham, F. D., Riccardi, C. J., Keough, M. E., \& Timpano, K. R. (2012). Excessive reassurance seeking and anxiety pathology: Tests of incremental associations and directionality. Journal of Anxiety Disorders, 26, 117-125. doi:10.1016/j.janxdis.2011.10.001

Craske, M.G., Kircanski, K., Zelikowsky, M., Mystkowski, J., Chowdhury, N., \& Baker, A. (2008). Optimizing inhibitory learning during exposure therapy. Behaviour Research and Therapy, 46(1), 5-27.

David, D. \& Hofmann, S (2013). Another error of Descartes? Implications for the "third wave" cognitive-behavioral therapy. Journal of Cognitive and Behavioral Psychotherapies, 13(1), 115-124

Deacon, B. J., Sy, J., Lickel, J. J., \& Nelson, E. O. (2010). Does the judicious use of safety behaviors improve the efficacy and acceptability of exposure therapy for claustrophobic fear? Journal of Behavior Therapy and Experimental Psychiatry, 41, 71-80.

Fals-Stewart, W., Marks, A. P., \& Schafer, J. (1993). A comparison of behavioral group therapy and individual behavior therapy in treating obsessive-compulsive disorder. The Journal of Nervous and Mental Disease, 181(3), 189-193.

Flannery-Schroeder, E. C., \& Kendall, P. C. (2000). Group and individual cognitive-behavioral treatments for youth with anxiety disorders: A randomized clinical trial. Cognitive Therapy and Research, 24(3), 251-278.

Foa, E. B., Jameson, J. S., Turner, R. M., \& Payne, L. L. (1980). Massed vs. spaced exposure sessions in the treatment of agoraphobia. Behaviour Research and Therapy, 18(4), 333-338.

Foa, E. B., Hembree, E. A., Cahill, S. P., Rauch, S. A., Riggs, D. S., Feeny, N. C., \& Yadin, E. (2005). Randomized trial of prolonged exposure for posttraumatic stress disorder with and without cognitive restructuring: outcome at academic and community clinics. Journal of Consulting and Clinical Psychology, 73(5), 953.

Foa, E.B., Huppert, J.D. \& Cahill, S.P. (2006). Emotional processing theory: An update. In B.O. Rothbaum (ed.), Pathological anxiety: Emotional processing in etiology and treatment (pp. 3-24). New York: Guilford.

Gilliam, C. M., Diefenbach, G. J., Whiting, S. E., \& Tolin, D. F. (2010). Stepped care for obsessive-compulsive disorder: An open trial. Behaviour Research and Therapy, 48, 1144-1149. doi:10.1016/j.brat.2010.07.010 
Advances and Controversies in the Application of a Modified Version

Hayes, S. C., Strosahl, K. D., \& Wilson, K. G. (1999). Acceptance and commitment therapy: An experiential approach to behavior change. New York: Guilford Press.

Herbert, J. D., Rheingold, A. A., Gaudiano, B. A., \& Myers, V. H. (2004). Standard versus extended cognitive behavior therapy for social anxiety disorder: A randomized-controlled trial. Behavioural and Cognitive Psychotherapy, 32(02), 131-147.

Hirsch, C., Meynen, T., \& Clark, D. M. (2004). Negative self - imagery in social anxiety contaminates social interactions. Memory, 12, 496-506. doi:10.1080/09658210444000106

Hofmann, S. G. (2008). Acceptance and commitment therapy: New wave or morita therapy? Clinical Psychology: Science and Practice, 15, 280-285. doi:10.1111/j.14682850.2008.00138.x

Hofmann, S. G., \& Asmundson, G. J. G. (2008). Acceptance and mindfulness-based therapy: New wave or old hat? Clinical Psychology Review, 28, 1-16. doi:10.1016/j.cpr.2007.09.003

Jensen, V. L., Hougaard, E., \& Fishman, D. B. (2013). Sara, a social phobia client with sudden change after exposure exercises in intensive cognitive-behavior group therapy: A casebased analysis of mechanisms of change. Pragmatic Case Studies in Psychotherapy, Vol. 9 (3), Article 1, 275-336. Available: http://hdl.rutgers.edu/1782.1/pcsp_journal

Johnstone, K. A., \& Page, A. C. (2004). Attention to phobic stimuli during exposure: The effect of distraction on anxiety reduction, self-efficacy and perceived control. Behaviour Research and Therapy, 42, 249-275. doi:10.1016/S0005-7967(03)00137-2

Krupnick, J. L., Sotsky, S. M., Simmens, S., Moyer, J., Elkin, I., Watkins, J., \& Polkonis, P. A. (1996). The role of the therapeutic alliance in psychotherapy and pharmacotherapy outcome: Findings in the National Institute of Mental Health Treatment of Depression Collaborative Research Program. Journal of Consulting and Clinical Psychology, 64, 532-539. doi:10.1037/0022-006X.64.3.532

Lohr, J. M., Olatunji, B. O., \& Sawchuk, C. N. (2007). A functional analysis of danger and safety signals in anxiety disorders. Clinical Psychology Review, 27, 114-126. doi:10.1016/j.cpr.2006.07.005

Masheb, R. M., \& Grilo, C. M. (2007). Rapid response predicts treatment outcomes in binge eating disorder: Implications for stepped care. Journal of Consulting and Clinical Psychology, 75, 639-644. doi:10.1037/0022-006X.75.4.639

Milosevic, I., \& Radomsky, A. S. (2008). Safety behaviour does not necessarily interfere with exposure therapy. Behaviour Research and Therapy, 46, 1111-1118. doi:10.1016/j.brat.2008.05.011

Moscovitch, D. A. (2009). What is the core fear in social phobia? A new model to facilitate individualized case conceptualization and treatment. Cognitive and Behavioral Practice, 16, 123-134. doi:10.1016/j.cbpra.2008.04.002

Muller, K. L., \& Schultz, L. T. (2012). “Selling” exposure therapy. Pragmatic Case Studies in Psychotherapy, 8 (4), Article 3, 288-295. Available: http://hdl.rutgers.edu/1782.1/pcsp_journal

Oliver, N. S., \& Page, A. C. (2003). Fear reduction during in vivo exposure to blood-injection stimuli: Distraction vs. attentional focus. British Journal of Clinical Psychology, 42, 1325. doi:10.1348/014466503762841986 
Advances and Controversies in the Application of a Modified Version

Orr, E. M. J., \& Moscovitch, D. A. (2013). Physical appearance anxiety impedes the therapeutic effects of video feedback in high socially anxious individuals. Behavioural and Cognitive Psychotherapy, 15, 1-13. doi:10.1017/S1352465812001038

Parrish, C., Radomsky, A., \& Dugas, M. (2008). Anxiety-control strategies: Is there room for neutralization in successful exposure treatment? Clinical Psychology Review, 28, 14001412. doi:10.1016/j.cpr.2008.07.007

Rachman, S., Radomsky, A. S., \& Shafran, R. (2008). Safety behaviour: A reconsideration. Behaviour Research and Therapy, 46, 163-173. doi:10.1016/j.brat.2007.11.008

Rachman, S., Shafran, R., Radomsky, A. S., \& Zysk, E. (2011). Reducing contamination by exposure plus safety behaviour. Journal of Behavior Therapy and Experimental Psychiatry, 42, 397-404. doi:10.1016/j.jbtep.2011.02.010

Roemer, L., \& Orsillo, S. M. (2002). Expanding our conceptualization of and treatment for generalized anxiety disorder: Integrating mindfulness/acceptance-based approaches with existing cognitive-behavioral models. Clinical Psychology: Science and Practice, 9, 5468. doi: 10.1093/clipsy.9.1.54

Salkovskis, P. M. (1991). The importance of behaviour in the maintenance of anxiety and panic: A cognitive account. Behavioural Psychotherapy, 19, 6-19. doi:10.1017/S0141347300011472

Steketee, G., Frost, R. O., Wincze, J., Greene, K. A., \& Douglass, H. (2000). Group and individual treatment of compulsive hoarding: A pilot study. Behavioural and Cognitive Psychotherapy, 28(3), 259-268.

Storch, E. A., Merlo, L. J., Lehmkuhl, H., Geffken, G. R., Jacob, M., Ricketts, E., ... \& Goodman, W. K. (2008). Cognitive-behavioral therapy for obsessive-compulsive disorder: A non-randomized comparison of intensive and weekly approaches. Journal of Anxiety Disorders, 22(7), 1146-1158.

Sy, J. T., Dixon, L. J., Lickel, J. J., Nelson, E. A., \& Deacon, B. J. (2011). Failure to replicate the deleterious effects of safety behaviors in exposure therapy. Behaviour Research and Therapy, 49, 305-314.

Ventis WL, Higbee G, Murdock SA. (2001). Using humor in systematic desensitization to reduce fear. Journal of General Psychology, 128(2):214-253

Wells, A., Clark, D. M., Salkovskis, P., Ludgate, J., Hackmann, A., \& Gelder, M. (1995). Social phobia: The role of in-situation safety behaviors in maintaining anxiety and negative beliefs. Behavior Therapy, 26, 153-161. doi:10.1016/S0005-7894(05)80088-7

Westra, H. A., Dozois, D. J. A., \& Marcus, M. (2007). Expectancy, homework compliance, and initial change in cognitive-behavioral therapy for anxiety. Journal of Consulting and Clinical Psychology, 75, 363-373. doi:10.1037/0022-006X.75.3.363

Wilson, G. T. (2006). Rapid response to cognitive behavior therapy. Clinical Psychology: Science and Practice, 6, 289-292. doi:10.1093/clipsy.6.3.289 